\title{
Uveal Melanoma in Asians: A Review
}

\author{
Pradeep Manchegowda ${ }^{\mathrm{a}}$ Arun D. Singh ${ }^{\mathrm{b}}$ Carol Shields ${ }^{\mathrm{c}}$ Swathi Kaliki ${ }^{\mathrm{d}}$ \\ Parag Shah ${ }^{\mathrm{e}}$ Lingam Gopal $^{f}$ Pukhraj Rishi ${ }^{g}$
}

aShri Bhagwan Mahavir Vitreoretinal Services, Sankara Nethralaya, Chennai, India; ${ }^{\mathrm{b} O p h t h a l m i c}$ Oncology, Cole Eye Institute, Cleveland Clinic, Cleveland, OH, USA; 'OCular Oncology Service, Wills Eye hospital, Thomas Jefferson University, Philadelphia, PA, USA; ' LV Prasad Eye Institute, Ocular Oncology Service, The Operation Eyesight Universal Institute of Eye Cancer, Hyderabad, India; ${ }^{e}$ Department of Pediatric Retina \& Ocular Oncology, Aravind Eye Hospital

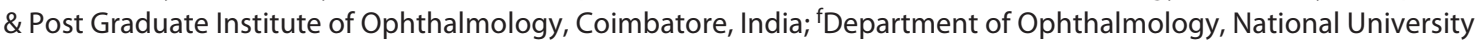
Hospital, Singapore, Singapore; ${ }^{9}$ Truhlsen Eye Institute, University of Nebraska Medical Centre, Omaha, NE, USA

\section{Keywords}

Eye $\cdot$ Uvea $\cdot$ Choroid · Iris · Tumor · Melanoma · Asian

\section{Abstract}

Despite limited data, some differences in the clinical profile can be observed in Asian population when compared with presentation of uveal melanoma (UM) in white population. The incidence of UM is higher in Whites than in Asians. For the purpose of comparison with Asian population, data from North America, Europe, and Australia were considered as that of "white" population. The annual incidence of UM has been reported to be $5-6$ cases/million in whites. The incidence in different parts of Asia is estimated at 0.2-0.6 per million. The age of presentation is around 40-55 years in Asians, which is younger when compared to that of whites (mean age of 58 years). At presentation, mean basal diameter of tumors in Asians is greater compared to whites but overall, medium-size tumors are most common. Clinical presentation is straightforward in majority of cases with retinal detachment, acute glaucoma, uveitis, cataract, or vitreous hemorrhage as common symptoms. Epithelioid cell-type variant carries the worst prognosis. Management options for choroidal melanoma include transpupillary thermotherapy, plaque radiotherapy, charged particle irradiation, local resection, enucleation, or orbital exenteration. Most commonly used modalities are enucleation and plaque radiotherapy.

(c) 2021 S. Karger AG, Basel

\section{Introduction}

Being uncommon in Asian population, uveal melanoma (UM) may be overlooked as a diagnostic consideration leading to delayed diagnosis causing visual loss and potential metastasis. Asia being the largest as well as the most populous continent in the world is diverse in its ethnicity and geography. The implications of this diversity make drawing uniform conclusions across populations impractical. However, there exist obvious differences in the presentation and outcomes of UM in Asians from that reported from Europe, North America, and Australia. For the purpose of comparison with Asian population, data from North America, Europe, and Aus-

$\begin{aligned} & \text { karger@karger.com } \\ & \text { www.karger.com/oop }\end{aligned}$
Karger $\%$

Pukhraj Rishi

Shri Bhagwan Mahavir Vitreoretinal Services

Sankara Nethralaya, 18 College Road

Tamil Nadu Chennai 6000016 (India)

docrishi@yahoo.co.in 
Table 1. Demographic profile of patients with UM in studies from Asian countries

\begin{tabular}{|c|c|c|c|c|c|c|c|c|c|}
\hline No. & Authors & Study type & Year & Country & $N$ & Population & $\begin{array}{l}\text { Gender } \\
\text { (male\%) }\end{array}$ & $\begin{array}{l}\text { Age in years } \\
\text { (range) }\end{array}$ & $\begin{array}{l}\text { Incidence } \\
\text { (per million/ } \\
\text { year) }\end{array}$ \\
\hline 2 & Liu et al. [11] & Retrospective hospital based & $2005-2015$ & China & 582 & Chinese & 49.3 & $44.6(5-77)$ & na \\
\hline 3 & Tomizuka et al. [7] & Review of registry & $2011-2013$ & Japan & 163 & Japanese & 50.3 & 63.5 & 0.64 \\
\hline 5 & Alsuhaibani [10] & Retrospective hospital based & $1983-2005$ & Saudi Arabia & 40 & Arabic & 60 & $50(24-77)$ & na \\
\hline 6 & Frenkel et al. [8] & Retrospective hospital based & $1988-2007$ & Israel & 558 & West Asian & 44.6 & $60.8(5-95)$ & 6.71 \\
\hline 7 & Liu et al. [6] & Retrospective hospital based & $1990-2005$ & Taiwan & 26 & Chinese & 42 & 50 & 0.6 \\
\hline 8 & Yue et al. [12] & Retrospective hospital based & 2003-2012 & China & 171 & Chinese & 49 & $48.6(14-83)$ & na \\
\hline 10 & Biswas et al. [14] & Retrospective hospital based & $1987-2001$ & India & 103 & Asian Indian & 61.16 & $45.7(14-82)$ & na \\
\hline 11 & Kashyap et al. [15] & Retrospective hospital based & 2001-2011 & India & 76 & Asian Indian & 51.3 & 46 & na \\
\hline 12 & Hamal et al. [16] & Prospective hospital based & 2017-2018 & Nepal & 8 & Nepali & 62.5 & $47(18-73)$ & na \\
\hline
\end{tabular}

No., number; S. Korea, South Korea; na, not available; UM, uveal melanoma.

tralia were considered as that of "white" population. This review article intends to compare the incidence, presentation, management, and outcomes of UM in Asians with that of whites.

\section{Method of Literature Search}

A literature search was carried out in PubMed database for all publications from 1980 to 2019 using the keywords "Uveal melanoma," "choroidal melanoma," "ciliary body melanoma," "iris melanoma," and "Asia." Countries were included from Asian geographical subregions, that is, north Asia, central Asia, western Asia, south Asia, east Asia, and southeast Asia. Non-English manuscripts were not included. It revealed 54 reports, of which 12 relevant studies that included demographic, clinical, histopathological profile of patients and being representative of individual countries were shortlisted. Further, literature search was carried by entering individual Asian country name as an additional keyword to avoid missing any study(ies). Data from the studies were tabulated.

\section{Epidemiology}

\section{Incidence}

The ancestral population of modern-day Asians has its origins in the 2 primary prehistoric settlement centers greater southwest Asia and the Mongolian plateau. Prominent ethnolinguistic groups include Mongols, Turkic, Indo-Aryans, Arabians in central Asia, Han, Tibetans, Joseon, Yamato in east Asia, Tartars, Paleo-Siberian in north, and Dravidians in south. Hence, studies must be analyzed by the ethnolinguistic population represented therein. The annual incidence of UM has been reported to be 5-6 cases/million in the USA, Europe, and Australia $[1,2]$. The incidence in different parts of Asia has been estimated to range between 0.25 and 0.64 per million [38]. A study by Kaneko [3] in Japanese population showed an incidence of 0.25 per million, although recent epidemiological studies in the Asian continent showed incidence of UM to be ranging from 0.42 to 0.64 per million [4-7]. On the other hand, a study in Israel showed a significantly higher incidence of 6.71 per million [8]. This is attributed to the predominant white Jewish population in the region and cannot be treated as reflection of Asian 

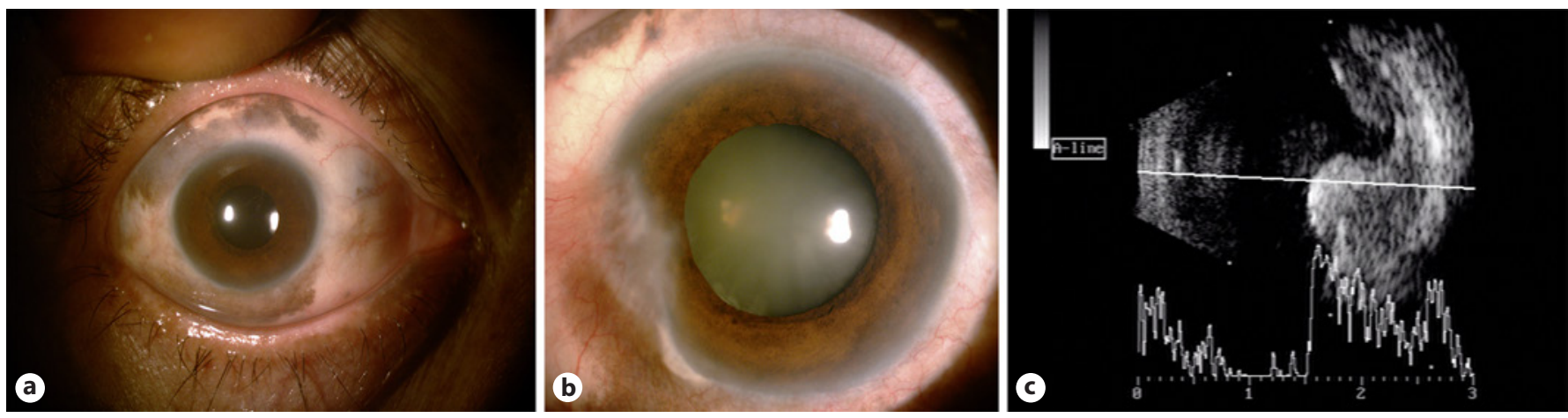

Fig. 1. External photograph reveals ocular melanocytosis (a), slit-lamp examination with diffuse illumination (b) reveals ectropion uveae, and ultrasound B-scan (c) reveals a large mushroom-shaped choroidal mass with acoustic hollowing. Vitreous echoes denote hemorrhage.

population, in general. The incidence rate of UM in Asian population is far below the reported incidence from the Europe, North America, and Australia.

\section{Age}

The mean age of presentation is around 42.9-63.5 years in Asians according to different studies [4-16]. Only 2 studies conducted in Japan and Israel have shown mean presenting age above 60 years $[7,8]$. In other studies, mean presenting age ranges between 42.9 and 54 years, which is a decade or 2 earlier compared to that of whites (mean age 58 years) [17]. It could be assumed that the age at presentation might likely get lower with implementation of improved screening strategies in Asian countries. Demographic data are summarized in Table 1.

\section{Sex}

$\mathrm{UM}$ is more common in males. Although a high incidence of $61 \%$ males was noted in the study by Biswas et al. [14], it was based on data collected from a tertiary-care referral hospital that does not reflect a true populationbased incidence. UM in males tends to be larger in size compared to that in females [18]. Some studies in white population showed a higher incidence of metastasis in males $[19,20]$. However, a large study in Chinese population did not show such an association with males [11].

\section{Race}

In comparison with whites, a lower incidence of UM in Asians is well documented, lying between that of Whites and Africans. The order of incidence as follows: Non-Hispanic whites $>$ Hispanics $>$ Asians $>$ Africans [1].

\section{Geographic Factors}

Blond hair with light eyes and skin along with higher latitudes [21] are some of the recognized risk factors. A lower incidence in pigmented Asian races and a higher incidence in predominantly white Israeli population points to possible risk factors beyond geographical limits [8].

\section{Genetics}

BAP-1 mutations linked to UM have been described as inheritable cases of melanoma in many studies. These cases tend to present at an early age and have predisposition for mesothelioma, cutaneous melanoma, renal cell carcinoma, breast, and ovarian malignancies [22]. Incidence of UM has remained stable in most White and Asian populations over several decades. However, a South Korean study showed statistically significant rise in the incidence during last decade of the study period [4]. A case series from China highlighted FAM11 1B and DSC2 gene mutations in patients with nevus of Ota having concomitant UM [23]. Yet, there is a lack of Asian studies reporting on the incidence of UM risk factors like familial cases or dysplastic nevus syndrome.

\section{Classification}

\section{Based on Tumor Size}

COMS (collaborative ocular melanoma study) classification was based on tumor size measured in terms of largest basal diameter, and height (thickness) of tumor [24]. As per size, medium-sized tumors are most common, followed by large-sized tumors, and small-sized tumors being the least common. Liu et al. [11] found 78\% of tumors to be of medium size. Many Asian studies have 
Table 2. Clinical characteristics of UM in studies from Asian countries

\begin{tabular}{|c|c|c|c|c|c|c|c|c|c|c|c|c|}
\hline 2 & Liu et al. [11] & $2005-2015$ & China & 582 & 94.2 & 5.7 & 0.2 & na & na & 1.1 & 77.9 & 21 \\
\hline 3 & Tomizuka et al. [7] & $2011-2013$ & Japan & 163 & 85.9 & 14.1 & & na & na & na & na & na \\
\hline 5 & Alsuhaibani [10] & $1983-2005$ & Saudi Arabia & 40 & 70 & 30 & 0 & $5-26$ & $3.2-16$ & 50 & 50 & 0 \\
\hline 6 & Frenkel et al. ${ }^{\mathrm{a}}[8]$ & $1988-2007$ & Israel & 558 & 86.9 & 16.8 & 6.6 & na & na & 9 & 64.5 & 17.9 \\
\hline 7 & Liu et al. [6] & 1990-2005 & Taiwan & 26 & 88 & 12 & 0 & 12 & 7.7 & na & na & na \\
\hline 8 & Yue et al. [12] & 2003-2012 & China & 171 & 98 & 2 & 0 & 11.8 & 8.6 & na & na & na \\
\hline
\end{tabular}

No., number; na, not available; S. Korea, South Korea; COMS, collaborative ocular melanoma study; Ch, choroid; CB, ciliary body; mm, millimeter; LBD, largest basal diameter; Ht, height; S, small; M, medium; L, large; UM, uveal melanoma. ${ }^{\text {a }} \%$ distribution in site of melanoma adds to $>100$ because of contiguous tumors. ${ }^{\mathrm{b}} 5.2 \%$ had ciliochoroidal melanoma.

shown a larger mean basal diameter in Asians compared to whites (Fig. 1) [14]. The mean largest basal diameter varied from 12 to $14.8 \mathrm{~mm}$ in various Asian studies (Table 2). Tumor size has been considered as the most significant factor for survival in a study involving 582 patients [25].

\section{Based on Histopathology}

Modified Callendar Classification is widely used histopathological classification of UM worldwide [26]. Studies from India [15, 27] and China [11] showed a higher incidence of spindle type tumor as compared to mixed celltype tumor. Table 3 summarizes the histopathological features and treatment modalities in various Asian studies.

\section{Based on Molecular Testing \\ - Class 1}

- Class 2

Or

- Disomy 3 and 8

- Monosomy 3 and 8q gain

Molecular studies using gene expression and chromosomal aberration analysis have helped to stratify UM into 2 prognostic classes. Class 1 tumors or disomy 3 (D3) pos- sess low risk of liver metastasis whereas Class 2 tumors or with monosomy 3 (M3) have a high risk of liver metastasis. In addition to chromosome 3 , aberrations in chromosomes 1 and 8 also have been studied in UM [28-30]. Abnormalities in the HLA class I, $\beta 2-\mathrm{m}$, and HLA class II antigens have been reported in UM by an Indian study group [31]. Another study from India [32] highlights the significance of antigen processing molecules in $\mathrm{MHC}$ class I expression in UM.

\section{Clinical Presentation}

\section{Symptoms}

Persistent photopsia (flashes), floaters, visual field loss, and diminution of vision are the frequent symptoms reported in Asian studies. Patients may develop pain secondary to glaucoma, orbital involvement, tumor-related inflammation, or necrosis [33]. About $20-25 \%$ of patients remain asymptomatic or tumor is detected as an accidental finding during routine fundus examination. Hence, indirect ophthalmoscopic evaluation of the dilated fundus is essential for identification and for followup of progressive benign lesions. In majority of Asian nations, UMs are detected late due to inadequate screening [34]. 
Table 3. Histopathological features and treatment modalities of UM in studies from Asian countries

\begin{tabular}{|c|c|c|c|c|c|c|c|c|c|c|c|c|}
\hline 1 & Liu et al. [6] & 2005-2015 & China & 582 & 71.3 (na) & 20.4 & 8.2 & 10 & 0 & 71.7 & 10.7 & 17.6 \\
\hline 2 & Zewar et al. [9] & 2006-2014 & Jordan & 46 & $28(\mathrm{I})$ & 39 & 0 & 4.3 & 0 & 10 & 20 & 70 \\
\hline 4 & Frenkel et al. [8] & 1988-2007 & Israel & 558 & $74(\mathrm{Ru})$ & 17.9 & 2.5 & 6.1 & 5.5 & na & na & na \\
\hline 5 & Liu et al. [6] & 1990-2005 & Taiwan & 26 & 0 & 100 & 0 & 0 & 0 & 23 & 77 & 0 \\
\hline 6 & Wong et al. [13] & $2002-2017$ & Singapore & 11 & 18.2 (na) & 18.2 & 0 & 0 & 63.6 & 20 & 20 & 40 \\
\hline 7 & Biswas et al. [14] & $1987-2001$ & India & 103 & 0 & 100 & 0 & 0 & 0 & 35 & 10.7 & 54.3 \\
\hline
\end{tabular}

Studies by Park et al. [4] and Tomizuka et al. [7] were epidemiological studies and did not have treatment components. No., number; na, not available; $\mathrm{RT}$, radiation therapy; Enuc, enucleation; I, iodine-125; Ru, ruthenium-106.
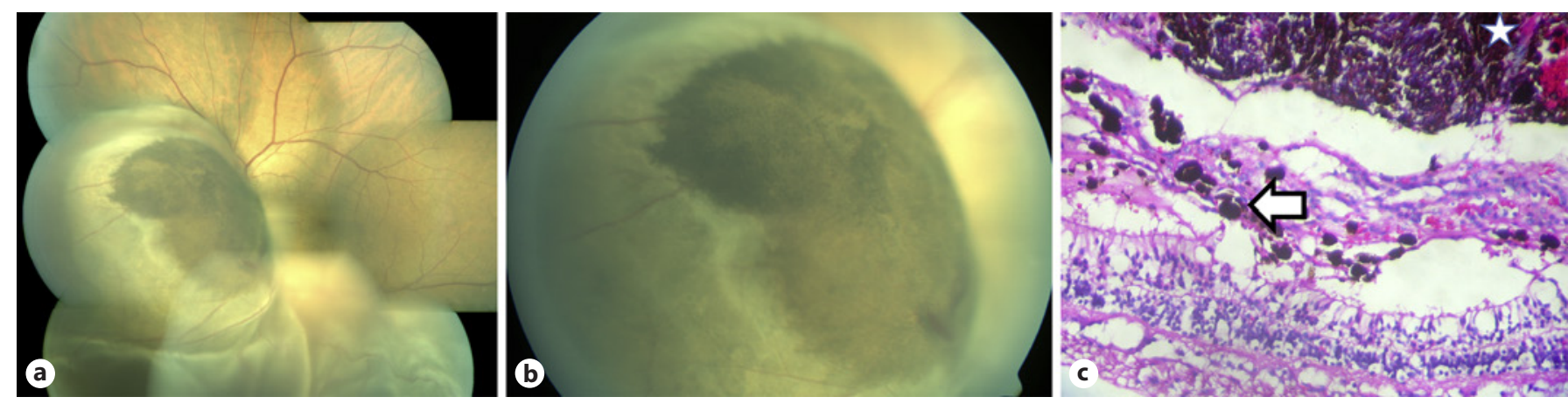

Fig. 2. Color fundus photograph (montage) reveals a large choroidal melanoma with optic disc overhang (a) and retinal invasion $(\mathbf{a}, \mathbf{b})$. Photomicrograph of the enucleated eye (Hematoxylin and eosin, $\times 10)$ reveals choroid (star) and pigmented tumor cells in the retina (arrow; c).

\section{Signs}

UM presents as a typical lesion in majority of cases. Some patients present with retinal detachment, acute glaucoma, uveitis, cataract, or vitreous hemorrhage (Fig. 1) [35, 36]. On the other hand, some other conditions may masquerade as UM, for example, choroidal detachment, choroidal hematoma, or hemorrhagic intraretinal macrocyst $[37,38]$. Asian studies show similar characteristics of tumor morphology in comparison to that of whites $[4,11]$.

Local invasion of choroidal melanoma is frequent with larger tumors. Choroidal tumor close to optic disc and ora serrata commonly erode and involves the overlying retina (Fig. 2). Iris involvement was seen in $4 \%$ of UM cases in a large case series from the USA. This study highlights increases incidence of iris melanoma in children [39]. There is paucity of studies from Asia concentrating entirely on iris melanoma. A large study from China showed iris involvement in $0.2 \%$ of UM cases [11], while another study from Israel showed iris involvement in $6.6 \%$ of cases [8]. This difference can be attributed to the disparate ethnicity of the 2 countries. None of the other studies reported in iris involvement. Hence, variation in 
Fig. 3. Forrest plot showing the mean and range of age at presentation among the 12 Asian studies described, with a weighted mean (red box) at the bottom.

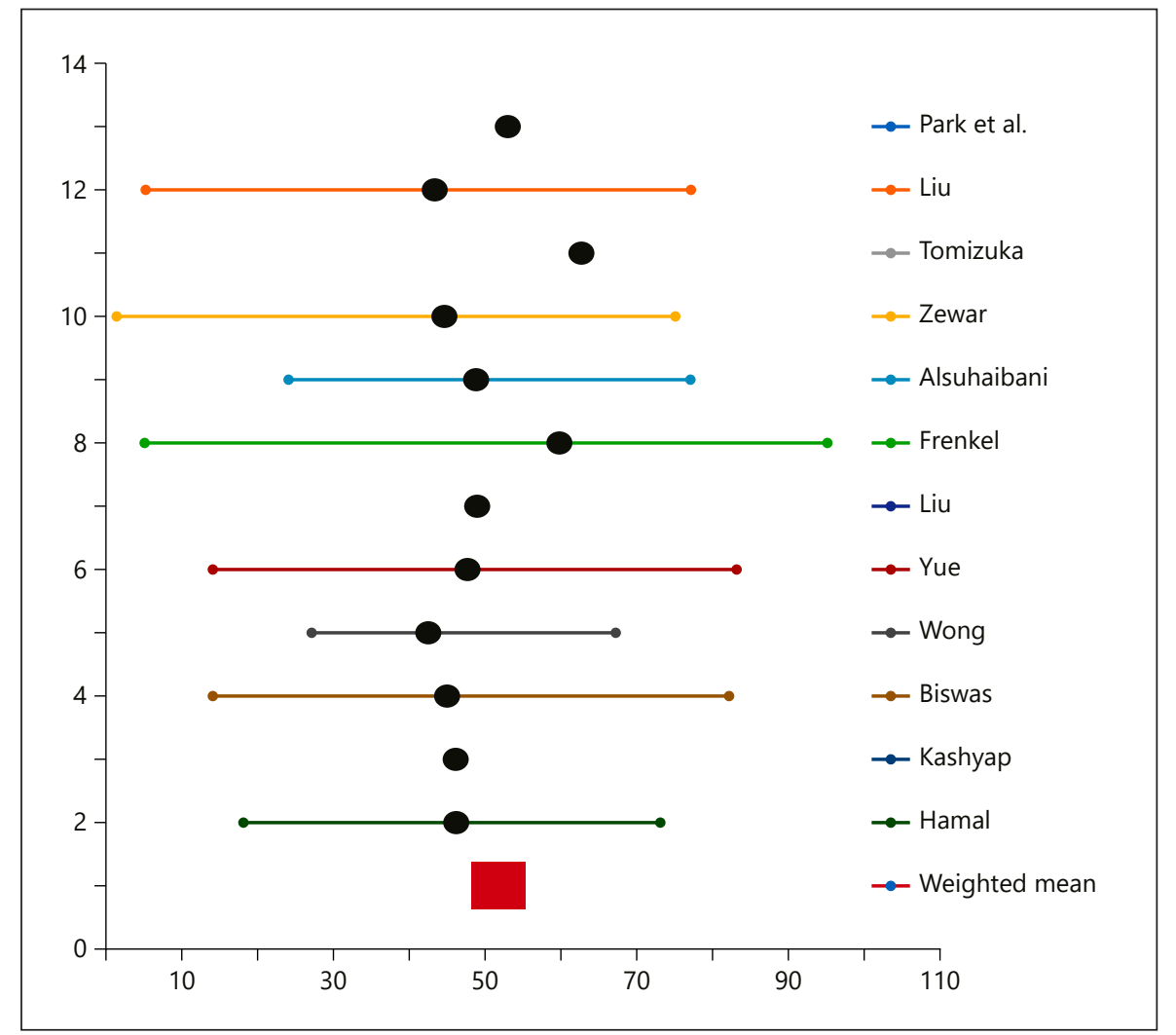

incidence of iris melanoma is not documented from Asian countries. Patients with Nevus of Ota are known to be at higher risk for UM (Fig. 1). This has been reported in a Chinese study as well [23]. This case series described $\mathrm{UM}$ in 3 patients with nevus of Ota and also novel genetic mutations like FAM111B and DSC2 which might contribute to etiology of disease. Figure 3 shows a Forrest plot depicting the mean and range of age at presentation amongst the 12 Asian studies described.

\section{Diagnosis}

Diagnosis of UMs is clinical, and investigations are usually needed for confirmation, documentation, followup, and prognosis estimation. In some circumstances, investigations are quite necessary, especially to differentiate diffuse melanoma from benign choroidal nevus. Ancillary testing commonly used are fundus photography, BScan ultrasound, fundus fluorescein angiography, indocyanine green angiography, enhanced depth imaging optical coherence tomography, swept-source OCT, autofluorescence, and fine-needle aspiration biopsy [40]. Since diagnosis of UM is clinical, its relative rarity in
Asians and unfamiliarity of clinical features among ophthalmologists increases the chances of initial misdiagnosis [13].

\section{Treatment}

Choices for choroidal melanoma are determined by tumor size and include transpupillary thermotherapy, plaque radiotherapy, charged particle irradiation, local resection, enucleation, or orbital exenteration. Most commonly used modalities are enucleation and focal radiotherapy (plaque therapy). In Asian context, primary enucleation is the most commonly used modality of treatment as listed in (Table 3) except in China and Israel $[8,11]$ where brachytherapy is more commonly used. Limiting factors in seeking treatment are lack of financial support and limited access to treatment in these regions. Commonly used radioisotopes for plaque radiation therapy are iodine-125 $\left({ }^{125} \mathrm{I}\right)$ and ruthenium-106 $\left({ }^{106} \mathrm{Ru}\right)$. Advantages of ${ }^{106} \mathrm{Ru}$ are its relative ease of availability, long shelf-life, ease of reuse, and its sparing effect on surrounding healthy tissues. A study conducted among Asian Indians comparing enucleation versus 
Table 4. Treatment outcomes of UM in studies from Asian countries

\begin{tabular}{llllllllll}
\hline No. & Authors & Year & Country & No. $\begin{array}{l}\text { Metasta- } \\
\text { sis, } \%\end{array}$ & $\begin{array}{l}\text { Deaths, } \\
\%\end{array}$ & $\begin{array}{l}5 \text { year } \\
\text { survival } \\
\text { rate }\end{array}$ & $\begin{array}{l}\text { Mean } \\
\text { follow-up, } \\
\text { months }\end{array}$ & Remarks \\
\hline 1 & Liu et al. [11] & $2005-2015$ & China & 582 & 8.4 & 5.5 & 92.7 & $30(1-124)$ & Tumor size significant for survival \\
\hline 2 & Zewar et al. [9] & $2006-2014$ & Jordan & 46 & 11 & 8.7 & na & $27(6-72)$ & - \\
\hline 3 & AlSuhaibani [10] & $1983-2005$ & Saudi Arabia & 40 & 5 & 0 & na & $33.7(0.5-120)$ & - \\
\hline 4 & Frenkel et al. [8] & $1988-2007$ & Israel & 558 & 13.3 & 17.4 & 88.6 & 66.6 & $\begin{array}{l}\text { Time from diagnosis to metastasis: } \\
35 \text { months }\end{array}$ \\
\hline 5 & Liu et al. [6] & $1990-2005$ & Taiwan & 26 & 12 & 12 & 53 & $39.5(2-176)$ & $\begin{array}{l}\text { CB involvement, nonspindle cell } \\
\text { type had poor prognosis }\end{array}$ \\
\hline 6 & Yue et al. [12] & $2003-2012$ & China & 171 & 21 & 17.5 & 80 & $63.4(6.4-140)$ & $\begin{array}{l}\text { BAP1 negative staining had worse } \\
\text { prognosis }\end{array}$ \\
\hline 7 & Wong et al. [13] & $2002-2017$ & Singapore & 11 & 45.5 & 36.4 & na & 29 (5-475) & $\begin{array}{l}\text { Time from diagnosis to metastasis: } \\
79.6(0-267) \text { months }\end{array}$ \\
\hline 8 & Biswas et al. [14] & $1987-2001$ & India & 103 & na & 0.96 & na & na & - \\
\hline 9 & MeeraLakshmi [27] & $2008-2015$ & India & 44 & na & 6.8 & 89 & 39 (6-86) & - \\
\hline
\end{tabular}

Studies by Park et al. [4] and Tomizuka et al. [7] were epidemiological studies and did not have treatment components.

brachytherapy yielded similar survival rates in both groups and intergroup observations were not statistically significant [27]. Local resection of tumor has been described in the literature. Although endoresection has been controversial due to chances of dissemination, a case series has shown good results with few recurrences [41]. There are only 3 studies from Asia which included endoresection procedure among which 1 is a large case series from China by Liu et al. [11] with $8 \%$ of UM patients.

Other treatment modalities described are proton beam therapy (PBT), carbon ion therapy, and gamma knife surgery. A study from Korea evaluated outcomes of PBT in 24 treatment naïve patients [42]. This study concluded that local control rate and acceptable toxicity in Korean patients were comparable with those in the previously reported PBT series. Charged particle irradiation has also been tried in treatment of UM. A study from Japan involving 116 patients utilized carbon ion radiation therapy in locally advanced and unfavorable tumors, and the results were satisfactory in terms of local tumor control (92.8\%), globe survival (92.8\%), and toxicity [43]. Gamma knife surgery has been tried in a series of patients with choroidal melanoma [44]. Although the outcomes with these 3 treatment modalities are similar to those of plaque brachytherapy, they remain way less popular when compared to plaque brachytherapy in this part of the world-likely because of the high capital cost involved.

\section{Prognosis}

It is well known that Asian patients have a higher mean basal diameter compared to whites, and hence, they are at more risk for metastases as well [17]. Liu et al. [11] found tumor size as significant factor for patient survival. However, the genetic makeup of tumors may be an important determinant for metastatic risk and prognostication. This needs further study in Asian population. Treatment outcomes are summarized in (Table 4).

To summarize, even though the incidence of UM in Asians is lower than that reported from white population in the USA, Europe, and Australia, it can vary in the context of the ethnolinguistic group the data are collected from. The age at presentation is younger than that of whites. At presentation, the mean basal diameter of tumor in Asians is greater compared to whites, but overall, medium-sized tumors are most common. Clinical presentation is straightforward, but some patients present with retinal detachment, acute glaucoma, uveitis, cataract, or vitreous hemorrhage. Most commonly used mo- 
dalities for treatment are enucleation and plaque radiotherapy limited by access. Future efforts must be directed toward early diagnosis of UM improve access to eye conserving therapies.

\section{Statement of Ethics} close.

The authors declare that they have no ethical conflicts to dis-

\section{Conflict of Interest Statement}

The authors declare that they have no conflicts of interest to disclose. Prof. Singh (as one co-author) is the Editor-in-Chief of the journal Ocular Oncology and Pathology.

\section{Funding Source}

The authors did not receive any funding.

\section{Authors Contribution}

P.T.M.: literature searches, analysis of the data, wrote the first draft, and manuscript revision. A.D.S.: substantial revision of the manuscript. C.L.S.: contribution to the manuscript revision. S.K.: manuscript revision. P.K.S.: manuscript revision. L.G.: substantial revisions of the manuscript. P.R.: substantial contributions to the conception or design of the work, literature searches, analysis of the data, interpretation of the data, and revising the manuscript critically for important intellectual content. All authors approved the final version as submitted.

\section{References}

$1 \mathrm{Hu}$ DN, Yu GP, McCormick SA, Schneider S, Finger PT. Population-based incidence of uveal melanoma in various races and ethnic groups. Am J Ophthalmol. 2005;140(4):612-7.

2 Singh AD, Turell ME, Topham AK. Uveal melanoma: trends in incidence, treatment, and survival. Ophthalmology. 2011;118(9):1881-5.

3 Kaneko A. Incidence of malignant melanoma of the eye in Japan, 1972-1976. Jpn J Clin Ophthalmol. 1979;33:941-7.

4 Park SJ, Oh CM, Kim BW, Woo SJ, Cho H, Park KH. Nationwide incidence of ocular melanoma in South Korea by using the national cancer registry database (1999-2011). Invest Ophthalmol Vis Sci. 2015;56(8):4719-24.

5 Cheng CY, Hsu WM. Incidence of eye cancer in Taiwan: an 18-year review. Eye. 2004;18(2): 152-8.

6 Liu YC, Tsai CC, Lee FL, Lee SM, Kao SC. Mortality from uveal melanoma treated by enucleation: a 16-year survey in Taiwan. Acta Ophthalmol. 2013;91(7):e583-4.

7 Tomizuka T, Namikawa K, Higashi T. Characteristics of melanoma in Japan: a nationwide registry analysis 2011-2013. Melanoma Res. 2017;27(5):492-7.

8 Frenkel S, Hendler K, Pe'er J. Uveal melanoma in Israel in the last two decades: characterization, treatment and prognosis. Isr Med Assoc J. 2009;11(5):280-5.

9 Zewar A, Nawaiseh I, Jaradat I, Khzouz J, Alrawashdeh K, AbdeeN G, et al. Management and outcome of uveal melanoma in a single tertiary cancer center in Jordan. Turk Patoloji Derg. 2016;32(3):186-92.

10 Alsuhaibani AH. Uveal melanoma in the Saudi Arabian population: two decades of management at the King Khaled eye specialist hospital. Saudi J Ophthalmol. 2009;23(2):157-63.
11 Liu YM, Li Y, Wei WB, Xu X, Jonas JB. Clinical characteristics of 582 patients with uveal melanoma in China. PLoS One. 2015;10(12): e0144562.

12 Yue H, Qian J, Yuan Y, Zhang R, Bi Y, Meng $\mathrm{F}$, et al. Clinicopathological characteristics and prognosis for survival after enucleation of uveal melanoma in Chinese patients: longterm follow-up. Curr Eye Res. 2017;42(5): 759-65.

13 Wong W, Sundar G, Chee C, Zhao PS, Rajagopalan R, Gopal L. Clinical spectrum, treatment and outcomes of uveal melanoma in a tertiary centre. Singapore Med J. 2019;60(9): 474-8.

14 Biswas J, Kabra S, Krishnakumar S, Shanmugam MP. Clinical and histopathological characteristics of uveal melanomas in Asian Indians. A study of 103 patients. Indian J Ophthalmol. 2004;52(1):41-4.

15 Kashyap S, Venkatesh P, Sen S, Khanduja S, Shrey D, Tinwala S, et al. Clinicopathologic characteristics of choroidal melanoma in a North Indian population: analysis of 10-year data. Int Ophthalmol. 2014;34(2):235-9.

16 Hamal D, Limbu B, Sthapit PR, Pradhan E, Shrestha R, Saiju R. Choroidal melanoma: our experience. Nepal J Ophthalmol. 2019;11(21): 64-73.

17 Shields CL, Kaliki S, Cohen MN, Shields PW, Furuta M, Shields JA. Prognosis of uveal melanoma based on race in 8100 patients: the 2015 Doyne Lecture. Eye. 2015;29(8):102735.

18 Damato BE, Coupland SE. Differences in uveal melanomas between men and women from the British Isles. Eye. 2012;26(2):292-9.

19 Zloto O, Pe'er J, Frenkel S. Gender differences in clinical presentation and prognosis of uveal melanoma. Invest Ophthalmol Vis Sci. 2013;54(1):652-6.
20 Rietschel P, Panageas KS, Hanlon C, Patel A, Abramson DH, Chapman PB. Variates of survival in metastatic uveal melanoma. J Clin Oncol. 2005;23(31):8076-80.

$21 \mathrm{Hu}$ DN, McCormick SA, Yu GP. Latitude and uveal melanoma. Ophthalmology. 2008; 115(4):757.

22 Masoomian B, Shields JA, Shields CL. Overview of BAP1 cancer predisposition syndrome and the relationship to uveal melanoma. J Curr Ophthalmol. 2018;30(2):102-9.

23 Pan X, Zheng S. Clinical and genetic characteristics of nevus of Ota with choroidal melanoma in Chinese. Ophthalmic Genet. 2019; 40(4):338-41.

24 Collaborative Ocular Melanoma Study Group. Design and methods of a clinical trial for a rare condition: the Collaborative Ocular Melanoma Study: COMS report no. 3. Control Clin Trials. 1993;14(5):362-91.

25 Diener-West M, Hawkins BS, Markowitz JA, Schachat AP. A review of mortality from choroidal melanoma: II. A meta-analysis of 5 -year mortality rates following enucleation, 1966 through 1988. Arch Ophthalmol. 1992; 110(2):245-50.

26 McLean IW, Foster WD, Zimmerman LE Gamel JW. Modifications of Callender's classification of uveal melanoma at the armed forces institute of pathology. Am J Ophthalmol. 1983;96(4):502-9.

27 Meeralakshmi P, Shah PK, Narendran V. Experiences of two different modalities in the management of choroidal melanoma in the Asian Indian population. South Asian J Cancer. 2017;6(3):134-6.

28 Radhakrishnan A, Badhrinarayanan N, Biswas J, Krishnakumar S. Analysis of chromosomal aberration $(1,3$, and 8$)$ and association of microRNAs in uveal melanoma. Mol Vis. 2009;15:2146-54. 
29 Shields CL, Say EAT, Hasanreisoglu M, Saktanasate J, Lawson BM, Landy JE, et al. Cytogenetic abnormalities in uveal melanoma based on tumor features and size in 1059 patients: the 2016 W. Richard Green lecture. Ophthalmology. 2017;124(5):609-18.

30 Shields CL, Say EAT, Hasanreisoglu M, Saktanasate J, Lawson BM, Landy JE, et al. Personalized prognosis of uveal melanoma based on cytogenetic profile in 1059 patients over an 8-year period: the 2017 Harry S. Gradle Lecture. Ophthalmology. 2017;124(10):1523-31.

31 Krishnakumar S, Abhyankar D, Lakshmi SA, Pushparaj V, Shanmugam MP, Biswas J. HLA expression in choroidal melanomas: correlation with clinicopathological features. Curr Eye Res. 2004;28(6):409-16.

32 Krishnakumar S, Abhyankar D, Sundaram AL, Pushparaj V, Shanmugam MP, Biswas J. Major histocompatibility antigens and antigen-processing molecules in uveal melanoma. Clin Cancer Res. 2003;9(11):4159-64.

33 Rishi P, Shields CL, Khan MA, Patrick K, Shields JA. Headache or eye pain as the presenting feature of uveal melanoma. Ophthalmology. 2013;120(9):1946-e2.
34 Ah-Fat FG, Damato BE. Delays in the diagnosis of uveal melanoma and effect on treatment. Eye. 1998;12 (Pt 5):781-2.

35 Eskelin S, Kivelä T. Mode of presentation and time to treatment of uveal melanoma in Finland. Br J Ophthalmol. 2002;86(3):333-8.

36 Rishi P, Appanraj R, Sharma T. Choroidal melanoma masquerading as multifocal central serous chorioretinopathy. Oman J Ophthalmol. 2016;9(3):187-8.

37 Bansal A, Rishi P, Paul SS, Saurabh K. Choroidal hematoma presenting as pseudo-uveal melanoma in a monocular 47-year old Asian Indian lady with opaque media. Oman J Ophthalmol. 2018;1(2):175-7.

38 Rishi P, Rishi E, Sen PR, Sharma T. Hemorrhagic intraretinal macrocyst: differential diagnosis and report of an unusual case. Oman J Ophthalmol. 2011;4(1):28-31.

39 Shields CL, Kaliki S, Shah SU, Luo W, Furuta $\mathrm{M}$, Shields JA. Iris melanoma: features and prognosis in 317 children and adults. J AAPOS. 2012 Feb 1;16(1):10-6.
40 Rishi P, Dhami A, Biswas J. Biopsy techniques for intraocular tumors. Indian J Ophthalmol. 2016;64(6):415-21.

41 Konstantinidis L, Groenewald C, Coupland SE, Damato B. Long-term outcome of primary endoresection of choroidal melanoma. $\mathrm{Br} \mathrm{J}$ Ophthalmol. 2014;98(1):82-5.

42 Kim TW, Choi E, Park J, Shin DH, Jung SK, Seok S, et al. Clinical outcomes of proton beam therapy for choroidal melanoma at a single institute in Korea. Cancer Res Treat. 2018;50(2):335-44.

43 Toyama S, Tsuji H, Mizoguchi N, Kamada T, Tsujii H, Tokumaru S, et al. Long-term result of carbon-ion radiation therapy for locally advanced or unfavorably located choroidal melanoma: CT Based 2-port orthogonal therapy can reduce the incidence of neovascular glaucoma. Int J Radiat Oncol Biol Phys. 2013 Jun 1;86(2):270-6.

44 Xu D, Liu D, Zhang Z, Zhang Y, Li Y, Liu X, et al. Gamma knife surgery in the management of orbital tumors. J NeuroSurg. 2010; 113 Suppl:34-8. 